\title{
Cellular and subcellular localization of the neuron-specific plasma membrane calcium ATPase PMCA1a in the rat brain
}

\author{
Katharine A. Kenyon ${ }^{1}$, Eric A Bushong ${ }^{2}$, Amy S. Mauer ${ }^{3}$, Emanuel E. Strehler ${ }^{3}$, Richard J. \\ Weinberg ${ }^{1,4}$, and Alain C. Burette ${ }^{1}$ \\ ${ }^{1}$ Department of Cell and Developmental Biology, University of North Carolina, Chapel Hill, NC \\ 27599, USA \\ ${ }^{4}$ Neuroscience Center, University of North Carolina, Chapel Hill, NC 27599, USA \\ 2 National Center for Microscopy and Imaging Research, Department of Neurosciences, \\ University of California, San Diego, La Jolla, California 92093 \\ 3 Department of Biochemistry and Molecular Biology, Mayo Clinic College of Medicine, \\ Rochester, MN 55905, USA
}

\begin{abstract}
Regulation of intracellular calcium is crucial both for proper neuronal function and survival. By coupling ATP hydrolysis with $\mathrm{Ca}^{2+}$ extrusion from the cell, the plasma membrane calciumdependent ATPases (PMCAs) play an essential role in controlling intracellular calcium levels in neurons. In contrast to PMCA2 and PMCA3, which are expressed in significant levels only in the brain and a few other tissues, PMCA1 is ubiquitously distributed, and is thus widely believed to play a "housekeeping" function in mammalian cells. Whereas the PMCA1b splice variant is predominant in most tissues, an alternative variant, PMCA1a, is the major form of PMCA1 in the adult brain. Here, we use immunohistochemistry to analyze the cellular and subcellular distribution of PMCA1a in the brain. We show that PMCA1a is not ubiquitously expressed, but rather is confined to neurons, where it concentrates in the plasma membrane of somata, dendrites and spines. Thus, rather than serving a general "housekeeping" function, our data suggest that PMCA1a is a calcium pump specialized for neurons, where it may contribute to the modulation of somatic and dendritic $\mathrm{Ca}^{2+}$ transients.
\end{abstract}

\section{Keywords}

calcium extrusion; calcium pump; immunohistochemistry; Cell Centered Database

\begin{abstract}
Transient changes in the intracellular concentration of free calcium $\left(\left[\mathrm{Ca}^{2+}\right]_{\mathrm{i}}\right)$ act to regulate or control numerous neuronal processes ranging from electrical excitability and neurotransmitter release (Neher and Sakaba, 2008, Spitzer et al., 2002), to dendritic integration and gene expression (Cohen and Greenberg, 2008, Larkum and Nevian, 2008). This versatility requires an elaborate "toolkit" of proteins to control the influx, efflux, and buffering of $\mathrm{Ca}^{2+}$ within and between cellular compartments, creating signals with widely different spatial and temporal profiles (Berridge et al., 2000; Friel and Chiel, 2008).

Maintaining optimal sensitivity and signal-to-noise ratios requires keeping $\left[\mathrm{Ca}^{2+}\right]_{i}$ very low $(\rho 100 \mathrm{nM})$ at rest. Moreover, prolonged $\mathrm{Ca}^{2+}$ overload can be lethal to neurons, activating $\mathrm{Ca}^{2+}$-sensitive protein-digesting enzymes and triggering membrane disintegration
\end{abstract}

Correspondence to: Alain Burette, Dept of Cell \& Developmental Biology, University of North Carolina, CB \# 7090, Chapel Hill, NC 27599; Phone: (919) 966 1277; Fax: (919) 966 1856; alain_burette@med.unc.edu. 
(Berliocchi et al., 2005). Perturbation of $\mathrm{Ca}^{2+}$ homeostasis is implicated in a variety of neuropathologies including stroke and Alzheimer's disease (Bezprozvanny and Mattson, 2008; Mattson, 2007). Not surprisingly, neurons use multiple strategies to deal with $\mathrm{Ca}^{2+}$ loads, including buffers (Schwaller et al., 2002), intracellular sinks (Verkhratsky, 2002), and membrane extrusion systems (Lytton, 2007; Strehler, 1990). As the sole high-affinity $\mathrm{Ca}^{2+}$ extrusion mechanism in the plasma membrane, the plasma membrane $\mathrm{Ca}^{2+}$ ATPases (PMCAs) play a key role in regulating $\left[\mathrm{Ca}^{2+}\right]_{i}$ (Di Leva et al., 2008).

Mammals express four isoforms of PMCA, encoded by four different genes (ATP2B1-4 in humans). The transcripts of these genes are subject to developmental and tissue-specific alternative splicing, resulting altogether in over 20 PMCA variants (Strehler and Zacharias, 2001). In vitro studies show that each isoform differs in its kinetics and affinity for $\mathrm{Ca}^{2+}$ and calmodulin. However, availability of calmodulin is but one of the factors that regulate PMCA activity in vivo. The isoforms also are differentially regulated by phosphorylation (e.g., via protein kinases A and C), by proteolysis, and by interactions with acidic phospholipids. These diverse regulatory mechanisms can shape the time course of $\mathrm{Ca}^{2+}$ signals (Strehler et al., 2007b). Accordingly, studies on naturally occurring mutants and PMCA "knockout" mice demonstrate that the PMCAs play distinct roles in tissue- and cellspecific dynamic $\mathrm{Ca}^{2+}$ handling. Current evidence suggests that the range of functions for the PMCAs is much wider than once envisioned: beyond their essential role in the maintenance of low $\left[\mathrm{Ca}^{2+}\right]_{\mathrm{i}}$ at rest, PMCAs are versatile tools that can shape local $\mathrm{Ca}^{2+}$ signals with high spatial and temporal resolution (Strehler et al., 2007a).

In situ hybridization and immunohistochemical studies reveal that each of the four PMCA isoforms is present in rat brain and exhibits distinct regional patterns of expression. Moreover, different neurons within a brain region can express a specific set of PMCAs, which can be precisely targeted to restricted domains. For example, in the cerebellar cortex, both PMCA2 and 3 concentrate in synaptic regions, but splice variant PMCA2b is postsynaptic, while PMCA2a and PMCA3 are largely presynaptic (Burette and Weinberg, 2007; Burette et al., 2009). Thus, neurons may control the type, amount, location, and activation of each PMCA according to their $\mathrm{Ca}^{2+}$ demands.

In contrast to PMCA2 and 3, PMCA1 is expressed in all adult tissues (Greeb and Shull, 1989; Stahl et al., 1992), suggesting that PMCA1 might play a fundamental housekeeping role in maintaining $\left[\mathrm{Ca}^{2+}\right]_{\mathrm{i}}$ at levels compatible with cell viability. This idea is supported by a PMCA1 knockout model, which is embryonic lethal very early in development (Okunade et al., 2004). Not surprisingly, PMCA1 is expressed in all brain regions. However, in contrast to other mammalian tissues, where the " $b$ " splice variant of PMCA1 (PMCA1b) predominates, PMCA1a is the main variant in the adult brain (see Fig. 1 for a diagram of the two splice variants). PMCA1b is expressed in the developing brain; but is progressively replaced by PMCA1a as the brain matures, reaching a steady state by about postnatal day 30 in the rat (Brandt and Neve, 1992, Kip et al., 2006). This led to the hypothesis that PMCA1a is the "synaptic" form of the enzyme, upregulated as synapses mature (Brandt and Neve, 1992).

To test whether PMCA1a is specifically associated with synapses, we used Western blots and immunohistochemistry to investigate its spatial distribution in the rat brain. We found that while PMCA1a is present at synapses, the pump is expressed at higher levels in the soma/dendritic compartment of many neurons throughout the brain, but is virtually absent in non-neuronal cells. 


\section{MATERIALS AND METHODS}

All procedures related to the care and treatment of animals were in accordance with institutional and NIH guidelines. All animals use protocol have been reviewed and approved by the Institutional Animal Care and Use Committee.

\section{Antisera}

The PMCA1a antibody (CR1a) was generated by immunizing New Zealand rabbits with keyhole limpet hemocyanin conjugated to a synthetic peptide (Filoteo et al., 1997). CR1a was generated against a 20-residue peptide sequence (VFSSSTASTPVGYPSGECIS, residues 1157-1176) in the carboxy terminus region of the rat PMCA1a (Fig. 1). The specificity of CR1a has been described (Filoteo et al., 1997) and was established by western blots using microsomes from COS cells overexpressing specific PMCAs, and further confirmed in microsomes from rat brain. CR1a recognizes only one band at $\sim 129 \mathrm{kDa}$ (Fig. 2A). Staining was absent in the presence of the peptide immunogen.

For GFAP (glial fibrillary acidic protein), we used a monoclonal antibody (catalog No. G6171, lot No. 037K4759, clone GA5, Sigma-Aldrich, St. Louis, MO) developed in mice immunized with purified GFAP from porcine spinal cord (Debus et al., 1983a). On western blots of whole-brain, GA5 shows a single band at $51 \mathrm{kDa}$ (Debus et al., 1983b). In paraformaldehyde-fixed tissue sections, the antibody stained only astrocytes in rat cerebellum and spinal cord and astrocytes in human optic nerve, brain, and astrocytoma sections (Debus et al., 1983a).

For ALdh1L1 (Aldehyde dehydrogenase family 1 member L1), we used a monoclonal antibody (catalog No. 75-164, lot No. 443-2KS-48, clone N103/31, NeuroMab, Davis, CA) developed using the full-length rat Aldh1L1 (from purified recombinant proteins expressed in insect cells using a baculovirus system).

Double labeling experiments show that all GFAP-positive cells also express ALdh1L1 (data not shown). However ALdh1L1 also labels many small cells not labeled for GFAP. Electron microscopy using preembedding immunogold labeling confirms that ALdh1L1 is only expressed in the cytoplasm of glial cells (data not shown). Together these data indicate that ALdh1L1 staining provides a robust marker for astrocytes (Cahoy et al., 2008).

\section{Western blots}

Freshly dissected brain regions (cerebellum, "forebrain" (including olfactory bulb, neocortex, striatum, and hippocampus) and "midbrain" (including thalamus and hypothalamus) from an adult (3 months) Sprague-Dawley rat were homogenized in RIPA buffer containing $150 \mathrm{mM} \mathrm{NaCl}, 0.1 \%$ SDS, $1 \% \mathrm{NP}-40,0.5 \%$ sodium deoxycholate, $50 \mathrm{mM}$ Tris, $\mathrm{pH}$ 8.0. Homogenates were centrifuged for $20 \mathrm{~min}$ at $13,000 \times g$ and the supernatants stored at $-80^{\circ} \mathrm{C}$ until use. Protein concentrations were determined using a BCA protein assay (Pierce). $30 \mu \mathrm{g}$ of protein was loaded per lane on a Nu-PAGE Bis-Tris 4-12\% gradient gel (Invitrogen) using NuPage MES (2-(N-morpholino) ethane sulfonic acid) running buffer. Proteins were transferred to a $0.45 \mu \mathrm{m}$ PVDF membrane using the Bio-RadR system with transfer buffer (700 mM glycine/25 mMTris-base/0.1\% SDS/20\% methanol) for 1.5 hours at $4{ }^{\circ} \mathrm{C}$ with ice pack at $60 \mathrm{~V}$. The membrane was blocked in $5 \%$ non-fat dry milk in $20 \mathrm{mM}$ Tris-HCl, pH 7.4, $150 \mathrm{mM} \mathrm{NaCl}, 0.05 \%$ Tween-20 (NFDM-TBST) at room temperature for 1 hour, and then incubated in primary antibody (CR1a rabbit polyclonal 1:2000; antiGAPDH mouse monoclonal 1:5000 (Research Diagnostics Inc., catalog No. 10-R-G109A)) overnight at $4{ }^{\circ} \mathrm{C}$ with gentle agitation. The blots were washed three times for five minutes using $1 \times$ TBST, followed by incubation with HRP-conjugated secondary antibody (goat anti-rabbit IgG 1:3000 (Santa Cruz Biotechnology sc-2054); goat anti-mouse IgG 1:5000 
(Santa Cruz Biotechnology sc-2055)) in 5\% NFDM-TBST for 1.5 hours at room temperature with gentle agitation. After washing four times for five minutes each with 1xTBST at room temperature, the immunoblots were developed using Western Lightning Chemiluminescence (Perkin Elmer catalog No. NEL101) following the manufacturer's protocol.

\section{Tissue Preparation}

Seven male Sprague-Dawley rats (200-350 g, Charles River, Raleigh, NC) were used for this study. After inducing deep anesthesia with sodium pentobarbital $(60 \mathrm{mg} / \mathrm{kg}$, i.p.), rats were intracardially perfused with heparinized saline followed by $500 \mathrm{ml}$ of fixative. Rats were fixed with $4 \%$ paraformaldehyde freshly-depolymerized in phosphate buffer ( $\mathrm{PB}, 0.1$ $\mathrm{M}, \mathrm{pH}$ 7.4) for light microscopy (LM); or with a mixture of $4 \%$ paraformaldehyde and $2 \%$ glutaraldehyde in $\mathrm{PB}$, for EM. Brains were then removed and postfixed $2 \mathrm{~h}$ at $4{ }^{\circ} \mathrm{C}$ in the same fixative. Brains were cut at 40-60 $\mu \mathrm{m}$ on a Vibratome and collected in cold PB.

\section{Light microscopy}

Free-floating sections were permeabilized with $50 \%$ ethanol for $30 \mathrm{~min}$ and then treated for 30 min with $3 \% \mathrm{H}_{2} \mathrm{O}_{2}$ in phosphate-buffered saline (PBS, $0.1 \mathrm{M}$, pH 7.4). After preincubation in $10 \%$ normal donkey serum (NDS, to block secondary antibody binding sites), sections were incubated in CR1a $(1: 1,000)$ overnight on a shaker at room temperature.

For immunoperoxidase microscopy, sections were then incubated for 3 hours in biotinylated secondary antibody (1:200; Jackson ImmunoResearch, West Grove, PA) and for 1 hour in ExtrAvidin-peroxidase complex (1:5,000; Sigma, St. Louis, MO); peroxidase was histochemically visualized with diaminobenzidine. Processed sections were mounted on gelatin-coated slides, air dried, and cleared with xylene before being coverslipped with D.P.X. mountant (BDH Chemicals, Poole, England).

For immunofluorescence microscopy, immunoreactivity was visualized by donkey IgG, conjugated to Cy-3 (1:200, Jackson ImmunoResearch; West Grove, PA) or by a goat IgG conjugated to Alexa 568 (1:200, Invitrogen; Carlsbad, CA). For double labeling, the second primary antibody $(1: 1,000$, mouse anti-GFAP or 1:1,000 anti-ALdh1L1) then was applied overnight and visualized by a secondary antibody conjugated to Cy5 (1:200, Jackson ImmunoResearch) or Alexa 568 (1:200, Invitrogen). Some sections were then counterstained with DAPI (Invitrogen) or Hoechst 33342 (Invitrogen) to visualize all cell nuclei and/or with NeuroTrace 640/660 (Invitrogen) to selectively visualize somata of neuron.

To study PMCA1a staining in relationship to the plasma membrane, we used the membrane tracer $\mathrm{DiO}$ (Invitrogen), which labels even the finest neuronal processes. DiO crystals were applied with a micropipette directly to some of the immunostained sections, which were then stored at $4^{\circ} \mathrm{C}$ for 24 to $72 \mathrm{~h}$.

Fluorescent sections were mounted on gelatin-coated slides, and directly coverslipped with Vectashield (Vector Lab, Burlingame, CA). To control for method specificity, some sections were processed as above, except that primary or secondary antibodies were omitted. In all such cases, staining was completely absent.

Sections were examined with a Leitz DMR microscope (Leica, Wetzlar, Germany). Images were acquired with a 12-bit cooled charge-coupled device camera (Retiga EX, QImaging, Canada) coupled to a Windows computer. 
For confocal microscopy, we used a Leica SP2 confocal microscope. Confocal stacks were then analyzed in 3D using ImageSurfer 1.13 (www.imageSurfer.org, for details see Feng et al., 2007).

We used Corel Draw v.12 (Corel, Ontario, Canada) to sharpen images (unsharp mask), adjust brightness and contrast, and compose final plates. These adjustments were done exclusively to enhance the presentation quality of figures, without altering the scientific data content of the images.

\section{Electron microscopy}

Floating sections were treated for $30 \mathrm{~min}$ in $1 \%$ sodium borohydride in PB to quench free aldehyde groups. The sections were incubated in $20 \%$ NDS for 30 min to suppress nonspecific binding, and then for $12 \mathrm{hr}$ in primary antibody (1:1,000), along with $2 \%$ NDS. After rinses in PBS, sections were incubated with biotinylated goat-anti rabbit IgG (1:200, Jackson ImmunoResearch), and then with $1.4 \mathrm{~nm}$ gold particles conjugated to streptavidin (1:50; Nanoprobes, Yaphank, NY) for $2 \mathrm{hr}$ at room temperature and rinsed in PBS. Sections were washed in $0.05 \mathrm{M} \mathrm{Na}$ acetate (to remove phosphate and chloride ions), followed by silver enhancement with IntenSE-M (Amersham Biosciences). Sections were then post-fixed in $0.5-1 \%$ osmium tetroxide in $0.1 \mathrm{M}$ PB for $35-45$ min and contrasted with $1 \%$ uranyl acetate in maleate buffer (0.1M, pH 6.0) for $1 \mathrm{hr}$. After dehydration in an ascending ethanol series and propylene oxide, sections were infiltrated with a mixture of Epon and Spurr resins (Electron Microscopy Sciences, Hatfield, PA) and flat-mounted between sheets of Aclar within glass slides. Seventy-nanometer sections were cut, mounted on 200 mesh copper grids, contrasted with uranyl acetate and Sato's lead, and examined in a Philips Tecnai electron microscope (Hillsboro, OR) at $80 \mathrm{kV}$; images were collected with a Gatan 12-bit $1024 \times 1024$ CCD camera (Pleasanton, CA).

\section{Large scale Mosaics}

DAB-labeled sections were imaged on an Olympus BX51WI equipped with a LEP automated stage (Hawthorne, NY). The mosaic was acquired using a 20X air (NA 0.75) objective using Neurolucida software (MBF Bioscience, Williston, VT) to control mosaic collection and processing. Fluorescent mosaics were acquired with an RTS 2000 high-speed photon system mounted on a T300 microscope (Nikon Inc, Melrille, NY) equipped with an Applied Precision (Issaquah, WA) automated stage. The whole slice mosaic was acquired with a 40X oil (NA 1.30) objective and the hippocampus mosaic was acquired with a $60 \mathrm{X}$ oil (NA 1.40) objective. The mosaic was acquired and reconstructed using software developed at NCMIR (https://confluence.crbs.ucsd.edu/display/ncmir/NCMIR+Software).

\section{RESULTS}

The abundance of PMCA1a in the rat brain was estimated by Western blot analysis (Fig. $2 \mathrm{~A})$. Equal amounts of protein lysate were loaded from various brain regions and the blotted proteins were probed with PMCA1a antibody. An antibody against glyceraldehyde-3phosphate dehydrogenase (GAPDH) was used as a protein-loading control. PMCA1a, detected as a protein of $\sim 130 \mathrm{kDa}$ throughout the brain, was expressed at comparable overall levels in the forebrain, midbrain/thalamus, and cerebellum.

PMCA1a distribution observed by immunohistochemistry on parasagittal sections (Fig. 2B) was generally consistent with the pattern observed by Western blotting; PMCA1a was most abundant in the neostriatum, thalamus and CA1 hippocampus, followed by cerebral cortex (Fig. 2B). As the necessarily limited size of figure 1B makes it difficult for the reader to evaluate immunostaining in detail, high resolution images of several parasagittal sections 
stained for PMCA1a were created using an automatic mosaic acquisition and processing system (Chow et al., 2006). These large-scale mosaics can be browsed through the CellCentered Database (Martone et al., 2002;Martone et al., 2008) at http://ccdb.ucsd.edu by selecting project ID:P2061 (record ID: MP7266, MP7351).

The overall distribution of PMCA1 a closely matched that using a pan-PMCA1 antibody (Burette et al., 2003) with the possible exception of the cerebellar cortex, where the panPMCA1 antibody showed weaker staining than the PMCA1a-specific antibody. We attribute this apparent discrepancy to the difference in sensitivity between the pan-PMCA1 used in the previous study and the splice-variant specific PMCA1a antibody used in the present study: western blot analysis and ELISA suggest that the CR1a is twice as sensitive as the PMCA1 antibody used in our previous study (Filoteo et al., 1997).

\section{Olfactory bulb}

The olfactory nerve was almost devoid of PMCA1a staining. In the glomerular layer, scattered cells were stained against a weakly stained background (Fig. 3). In the external plexiform layer, fine processes were strongly stained, in contrast to the mitral cell layer, where staining was dominated by somata.

\section{Cerebral cortex}

PMCA1a staining was seen throughout the cortical layers, strongest in layers I-III (Fig. 4A). Vertical lines of staining were prominent in layer IV (presumably representing apical dendrites of layer $\mathrm{V}$ pyramidal neurons). When examined at higher magnification, somata and dendrites were covered by a thin layer of PMCA1a staining (Fig. 4B). Neuronal cytoplasm was generally devoid of staining. Examination of material counterstained with NeuroTrace showed that not all somata were positive for PMCA1a. PMCA1a labeling was seen both in dendritic shafts and spines. Analysis of labeling intensity along the plasma membrane revealed that PMCA1a was not uniformly distributed; rather, regions of intense PMCA1a staining along the membrane were interspersed with regions of weak staining (Fig. 4C). We speculate that these patches of intense staining may correspond to specialized microdomains within the plasma membrane, since biochemical data suggest that PMCA isoforms may differentially associate with and be regulated by lipid raft domains (Sepulveda et al., 2006; Jiang et al., 2007).

\section{Hippocampus}

PMCA1a stained all hippocampal regions. A large-scale mosaic can be viewed through the Cell-Centered Database (record ID: MP7407). PMCA1a staining was observed throughout Ammon's horn, but as previously reported using a pan-PMCA1 antibody (Burette et al., 2003), staining was markedly stronger in CA1 than in CA2/3 (Fig. 4D). Intense staining was also observed in the outer blade of the molecular layer (Fig. 4D). Layers rich in somata (the pyramidal cell layer of Ammon's horn and granule cell layer in the dentate gyrus) were more weakly stained, perhaps reflecting the lower density of plasma membranes in these regions. At high magnification, PMCA1a staining appeared to be associated with somatic and dendritic plasma membranes (Fig. 4E-G).

\section{Neostriatum}

PMCA1a staining was strong in the caudate nucleus and putamen (Fig. 5A). Staining was prominent between the fascicles, which themselves were devoid of staining. At higher magnification, it was clear that PMCA1a stained the surface of somata and processes (Fig. $5 B)$. 


\section{Thalamus}

PMCA1a stained all thalamic regions robustly, with the exception of the thalamic reticular nucleus, where staining was very weak (Fig. 5C). At higher magnification PMCA1a staining could be seen to surround somata. In the neuropil, numerous small hollow profiles were seen, presumably representing cross-sections of large dendrites (Fig. 5D-E).

\section{Cerebellar cortex}

PMCA1a was detected in the molecular and granule cell layer, with little staining in the Purkinje cell layer (Fig. 6A, B). Punctate staining was seen throughout the molecular layer, outlining the proximal dendrites of Purkinje cells, which themselves seemed unstained. Granule cells were immunopositive, with staining associated with the plasma membrane. Synaptic glomeruli in the granule cell layer were also strongly stained (Fig. 6C).

\section{Brain stem}

PMCA1a was detected throughout the brain stem, though staining intensity varied across the different nuclei. Particularly strong staining was found in the cochlear nucleus $(\mathrm{CN})$ (Fig. 6D-F) and the facial nucleus (Fig. 6G). In the cochlear nucleus a dense band of PMCA1a labeling occupied the surface of the dorsal $\mathrm{CN}$ (fusiform cell layer and molecular layer), ending at the level of the granule cell lamina separating dorsal CN from the ventral CN (Fig. 6D). At higher magnification, PMCA1a staining could be seen on the plasma membrane of somata of small round cells, and dendrites running towards the surface of the dorsal $\mathrm{CN}$ and branching in the molecular layer (Fig. 6E,F). PMCA1a labeling was seen in both dendritic trunks and in spines. The size, distribution and shape of these labeled cells suggest that these were cartwheel cells (Wouterlood and Mugnaini, 1984). In the facial nucleus, motor neurons were intensely stained. Staining was associated with somatic and dendritic plasma membranes (Fig. 6G).

\section{Spinal cord}

PMCA1a staining was detected throughout the gray matter of the spinal cord (Fig. 7A). Staining was stronger in the dorsal than in the ventral horn, though relatively weak in lamina II (Fig. 7B). At higher magnification, PMCA1a could be seen on numerous thin processes, and associated with somata of some small cells (Fig. 7C). In the ventral horn, motor neurons were intensely stained (Fig. 7D). Staining was associated with the plasma membrane of both somata and dendrites (Fig. 7E). PMCA1a staining extended into the white matter, where thin processes radiating toward the ependyma were positive (Fig. 7D,E).

\section{Astrocytes}

The thin radial processes observed in the white matter of the spinal cord resemble the radially-oriented astrocytes previously described (Liuzzi and Miller, 1987). To determine more directly whether astrocytes contained PMCA1a we used multiple labeling with GFAP, the principal intermediate filament protein of mature astrocytes (Eng et al., 2000), and Aldh1L1, a pan-astrocyte marker (Cahoy et al., 2008). In the gray matter of the spinal cord, protoplasmic astrocytes stained for GFAP were immunonegative for PMCA1a (Fig. 8A,B). In the white matter, numerous fibrous astrocytic processes closely followed the PMCA1a positive processes but were themselves negative for PMCA1a (Fig. 8C-E). Similarly, in all other parts of the brain examined, we were unable to demonstrate unequivocal colocalization of PMCA1a with either GFAP or AlDh1L1 (Fig. 8F-I).

\section{Subcellular distribution}

The distribution of PMCA1a was further analyzed by electron microscopy, using preembedding immunogold labeling followed by silver intensification (Fig. 9). The majority of 
gold/silver particles coding for PMCA1a were associated with plasma membrane, generally lying on its cytoplasmic side (as would be expected, since the antibody was raised against an intracellular epitope). Numerous gold/silver particles coated the membrane of somata and dendrites. Labeling in dendrites extended into the spine membrane (insets, Fig. 9A, C). PMCA1a labeling was rarely seen within axon terminals, though it could occasionally be detected on the inner surface of myelinated and unmyelinated axons. However, PMCA1a labeling seemed excluded from active zones and the postsynaptic density. In agreement with the LM observations, glial somata and processes generally lacked labeling.

\section{DISCUSSION}

The present work provides the first report of the cellular and subcellular organization of PMCA1a, the main PMCA1 splice variant in the adult rat brain.

In contrast to PMCA2 and 3, which are mainly restricted to tissues such as muscle and nerve, PMCA1 is distributed throughout all adult tissues (Greeb and Shull, 1989; Stahl et al., 1992), leading to the suggestion that it plays a ubiquitous housekeeping function to maintain low resting levels of intracellular $\mathrm{Ca}^{2+}$ in most if not all mammalian cells. Intriguingly, while the "b" splice variant of PMCA1 predominates in all other adult tissues, it is not abundant in the adult brain (Filoteo et al., 1997) and is only expressed at high levels during development; as synapses mature, PMCA1b is replaced by PMCA1a (Brandt and Neve, 1992, Kip et al., 2006). This has led to the speculation that PMCA1 a may be a synapserelated protein. However, our results do not support this hypothesis: while we found PMCA1a in axon terminals and dendritic spines, it seemed absent from the synapse itself, as defined by the presynaptic active zone and the postsynaptic density. Thus, while PMCA1a was often present in the vicinity of the synaptic membrane, it did not appear to be a component of the pre-or post-synaptic multiprotein complexes comprising the active zone and postsynaptic density, respectively. This is in agreement with biochemical data, which have shown that the b- but not the a-splice variants of the PMCA can interact via a Cterminal PDZ domain binding motif with synaptic scaffold proteins like PSD-95 and PSD-93/chapsyn-110 (DeMarco and Strehler, 2001; Garside et al., 2009).

We found that PMCA1a is expressed throughout the brain, and its expression is restricted to neurons. While PMCA1 has been detected in primary cultures of rat cortical astrocytes (Fresu et al., 1999, Blaustein et al., 2002), our data show that glial cells express little or no PMCA1a in vivo. This is in accordance with earlier results that detected only the b-form of PMCA1 in rat cortical astrocytes (Fesu et al., 1999).

Surprisingly, not all neurons express PMCA1a. This is particularly well-illustrated in the dorsal cochlear nucleus, where staining appears restricted to cartwheel cells (Fig. 5E, F). Taken together, our data suggest that PMCA1a contributes to the functional optimization of $\mathrm{Ca}^{2+}$ handling in particular neurons rather than providing a general housekeeping function to maintain low resting intracellular $\left[\mathrm{Ca}^{2+}\right]$ in all cells.

PMCA1a was predominantly expressed in somata, dendrites and spines, suggesting its involvement in modulating soma-dendritic $\mathrm{Ca}^{2+}$ transients. Activity-dependent $\left[\mathrm{Ca}^{2+}\right]$ accumulation in the cytoplasm of dendrites and dendritic spines regulates a variety of neuronal functions, including synaptic signaling, induction of synaptic plasticity, and regulation of gene transcription (Bito and Takemoto-Kimura, 2003; Finkbeiner and Greenberg, 1998; Malenka and Nicoll, 1999; West et al., 2001; Yang et al., 1999). Along with mechanisms regulating $\mathrm{Ca}^{2+}$ influx and buffering, regulation of calcium extrusion plays a critical role for $\mathrm{Ca}^{2+}$-dependent signaling in neurons. PMCA is a major component of this specialized toolkit. In CA1 pyramidal neurons, PMCA dominates $\mathrm{Ca}^{2+}$ clearance from small 
dendrites and spines, and its activity-dependent regulation is directly involved in nonlinear $\mathrm{Ca}^{2+}$ signaling (Scheuss et al., 2006). Recent data suggest that differences in $\mathrm{Ca}^{2+}$ extrusion rate through PMCA play a major role in the differences in LTP observed between the CA1 and CA2 fields of the hippocampus (Simons et al., 2009). Our observation (see Fig. 3D) that pyramidal neurons in CA1 and CA2 express very different amounts of PMCA1a may be directly relevant to this functional difference. A specific role of PMCA1a in the hippocampus is also suggested indirectly by older data showing that PMCA1 expression in the CA1/CA3 pyramidal cells and the granule cells of dentate gyrus is differentially sensitive to kainic acid-induced seizures (Garcia et al., 1997).

The significance of the selective neuronal expression of PMCA1a as compared to PMCA1b is unclear. We speculate that PMCA1a may have enzymatic and regulatory properties that optimize $\mathrm{Ca}^{2+}$ economy in neurons. For example, PMCA1a and PMCA1b differ in $\mathrm{pH}$ sensitivity. PMCA1a, which contains a histidine-rich insert in its alternatively spliced Cterminal tail, binds $\mathrm{Ca}^{2+}$-calmodulin with higher affinity at lower $\mathrm{pH}$ (Kessler et al., 1992). Although total calmodulin levels are high in the brain (on the order of $10 \mu \mathrm{M}$ ), the free cellular calmodulin concentration is limiting (Persechini and Stemmer, 2002) and may not be sufficient to fully activate PMCA1a at neutral $\mathrm{pH}$. At reduced $\mathrm{pH}$, however, the higher calmodulin affinity of PMCA1a will allow more of the pump to be activated by the available calmodulin, resulting in increased $\mathrm{Ca}^{2+}$ extrusion. Indeed, activity dependent decreases in intracellular $\mathrm{pH}$ have been observed in a wide variety of neurons (Chesler, 2003), and the intracellular $\mathrm{pH}$ falls by 0.8-1.2 units during cerebral ischemia (Lipton, 1999; Yao and Haddad, 2004). The increased calmodulin affinity at reduced $\mathrm{pH}$ may allow the specialized PMCA1a isoform to continue to function even under these otherwise less favorable conditions.

\section{Supplementary Material}

Refer to Web version on PubMed Central for supplementary material.

\section{Acknowledgments}

NIH NS\#39444 (RJW), NS51769 (EES), 5R01GM082949-03 and NIDA DA016602 (MM).

KAK prepared and analyzed the microscopic material. ASM prepared the western blots. EAB processed the largescale mosaics. EES and RJW provided support. AB examined and analyzed the microscopic material, prepared plates, and wrote the manuscript. All authors helped with manuscript preparation.

The authors thank S. Grand and K. Phend for extensive histological support, A.G. Filoteo for the CR1a antibody, and M. Martone for extensive assistance with the Cell Centered Database.

\section{LITERATURE CITED}

Berliocchi L, Bano D, Nicotera P. $\mathrm{Ca}^{2+}$ signals and death programmes in neurons. Philos Trans R Soc Lond B Biol Sci. 2005; 360(1464):2255-2258. [PubMed: 16321795]

Berridge MJ, Lipp P, Bootman MD. The versatility and universality of calcium signalling. Nat Rev Mol Cell Biol. 2000; 1(1):11-21. [PubMed: 11413485]

Bezprozvanny I, Mattson MP. Neuronal calcium mishandling and the pathogenesis of Alzheimer's disease. Trends Neurosci. 2008; 31(9):454-463. [PubMed: 18675468]

Bito $\mathrm{H}$, Takemoto-Kimura S. $\mathrm{Ca}^{2+} / \mathrm{CREB} / \mathrm{CBP}-$ dependent gene regulation: a shared mechanism critical in long-term synaptic plasticity and neuronal survival. Cell Calcium. 2003; 34(4-5):425430. [PubMed: 12909086]

Blaustein MP, Juhaszova M, Golovina VA, Church PJ, Stanley EF. Na ${ }^{+} / \mathrm{Ca}^{2+}$ exchanger and PMCA localization in neurons and astrocytes: functional implications. Ann N Y Acad Sci. 2002; 976:356366. [PubMed: 12502582] 
Brandt P, Neve RL. Expression of plasma membrane calcium-pumping ATPase mRNAs in developing rat brain and adult brain subregions: evidence for stage-specific expression. J Neurochem. 1992; 59(4):1566-1569. [PubMed: 1328526]

Burette A, Rockwood JM, Strehler EE, Weinberg RJ. Isoform-specific distribution of the plasma membrane $\mathrm{Ca}^{2+}$ ATPase in the rat brain. J Comp Neurol. 2003; 467(4):464-476. [PubMed: 14624481]

Burette A, Weinberg RJ. Perisynaptic organization of plasma membrane calcium pumps in cerebellar cortex. J Comp Neurol. 2007; 500(6):1127-1135. [PubMed: 17183553]

Burette AC, Strehler EE, Weinberg RJ. "Fast" plasma membrane calcium pump PMCA2a concentrates in GABAergic terminals in the adult rat brain. J Comp Neurol. 2009; 512:500-513. [PubMed: 19025983]

Cahoy JD, Emery B, Kaushal A, Foo LC, Zamanian JL, Christopherson KS, Xing Y, Lubischer JL, Krieg PA, Krupenko SA, Thompson WJ, Barres BA. A transcriptome database for astrocytes, neurons, and oligodendrocytes: a new resource for understanding brain development and function. J Neurosci. 2008; 28(1):264-278. [PubMed: 18171944]

Chesler M. Regulation and modulation of pH in the brain. Physiol Rev. 2003; 83(4):1183-1221. [PubMed: 14506304]

Chow SK, Hakozaki H, Price DL, MacLean NA, Deerinck TJ, Bouwer JC, Martone ME, Peltier ST, Ellisman MH. Automated microscopy system for mosaic acquisition and processing. J Microsc. 2006; 222(Pt 2):76-84. [PubMed: 16774516]

Cohen S, Greenberg ME. Communication between the synapse and the nucleus in neuronal development, plasticity, and disease. Annu Rev Cell Dev Biol. 2008; 24:183-209. [PubMed: 18616423]

Debus E, Weber K, Osborn M. Monoclonal antibodies specific for glial fibrillary acidic (GFA) protein and for each of the neurofilament triplet polypeptides. Differentiation. 1983a; 25(2):193-203. [PubMed: 6198232]

Debus E, Weber K, Osborn M. Monoclonal antibodies to desmin, the muscle-specific intermediate filament protein. EMBO J. 1983b; 2(12):2305-2312. [PubMed: 6421570]

DeMarco SJ, Strehler EE. Plasma membrane $\mathrm{Ca}^{2+}$-ATPase isoforms $2 b$ and $4 b$ interact promiscuously and selectively with members of the membrane-associated guanylate kinase family of PDZ (PSD95/Dlg/ZO-1) domain-containing proteins. J Biol Chem. 2001; 276(24):21594-21600. [PubMed: 11274188]

Di Leva F, Domi T, Fedrizzi L, Lim D, Carafoli E. The plasma membrane $\mathrm{Ca}^{2+}$ ATPase of animal cells: structure, function and regulation. Arch Biochem Biophys. 2008; 476(1):65-74. [PubMed: 18328800]

Eng LF, Ghirnikar RS, Lee YL. Glial fibrillary acidic protein: GFAP-thirty-one years (1969-2000). Neurochem Res. 2000; 25(9-10):1439-1451. [PubMed: 11059815]

Feng D, Marshburn D, Jen D, Weinberg RJ, Taylor RM 2nd, Burette A. Stepping into the third dimension. J Neurosci. 2007; 27(47):12757-12760. [PubMed: 18032646]

Filoteo AG, Elwess NL, Enyedi A, Caride A, Aung HH, Penniston JT. Plasma membrane $\mathrm{Ca}^{2+}$ pump in rat brain. Patterns of alternative splices seen by isoform-specific antibodies. J Biol Chem. 1997; 272(38):23741-23747. [PubMed: 9295318]

Finkbeiner S, Greenberg ME. $\mathrm{Ca}^{2+}$ channel-regulated neuronal gene expression. J Neurobiol. 1998; 37(1):171-189. [PubMed: 9777740]

Fresu L, Dehpour A, Genazzani AA, Carafoli E, Guerini D. Plasma membrane calcium ATPase isoforms in astrocytes. Glia. 1999; 28(2):150-155. [PubMed: 10533058]

Friel DD, Chiel HJ. Calcium dynamics: analyzing the $\mathrm{Ca}^{2+}$ regulatory network in intact cells. Trends Neurosci. 2008; 31(1):8-19. [PubMed: 18054801]

Garcia ML, Murray KD, Garcia VB, Strehler EE, Isackson PJ. Seizure-induced alterations of plasma membrane calcium ATPase isoforms 1, 2 and 3 mRNA and protein in rat hippocampus. Mol Brain Res. 1997; 45:230-238. [PubMed: 9149097]

Garside ML, Turner PR, Austen B, Strehler EE, Beesley PW, Empson RM. Molecular interactions of the plasma membrane calcium ATPase 2 at pre-and post-synaptic sites in rat cerebellum. Neuroscience. 2009; 162:383-395. [PubMed: 19406213] 
Greeb J, Shull GE. Molecular cloning of a third isoform of the calmodulin-sensitive plasma membrane $\mathrm{Ca}^{2+}$-transporting ATPase that is expressed predominantly in brain and skeletal muscle. J Biol Chem. 1989; 264(31):18569-18576. [PubMed: 2530223]

Grichtchenko, Chesler M. Depolarization-induced alkalinization of astrocytes in gliotic hippocampal slices. Neuroscience. 1994; 62(4):1071-1078. [PubMed: 7845587]

Jiang L, Fernandes D, Mehta N, Bean JL, Michaelis ML, Zaidi A. Partitioning of the plasma membrane $\mathrm{Ca}^{2+}$-ATPase into lipid rafts in primary neurons: effects of cholesterol depletion. $\mathrm{J}$ Neurochem. 2007; 102(2):378-388. [PubMed: 17596212]

Kessler F, Falchetto R, Heim R, Meili R, Vorherr T, Strehler EE, Carafoli E. Study of calmodulin binding to the alternatively spliced $\mathrm{C}$-terminal domain of the plasma membrane $\mathrm{Ca}^{2+}$ pump. Biochemistry. 1992; 31:11785-11792. [PubMed: 1332771]

Kip SN, Gray NW, Burette A, Canbay A, Weinberg RJ, Strehler EE. Changes in the expression of plasma membrane calcium extrusion systems during the maturation of hippocampal neurons. Hippocampus. 2006; 16(1):20-34. [PubMed: 16200642]

Larkum ME, Nevian T. Synaptic clustering by dendritic signalling mechanisms. Curr Opin Neurobiol. 2008; 18(3):321-331. [PubMed: 18804167]

Lipton P. Ischemic cell death in brain neurons. Physiol Rev. 1999; 79(4):1431-1568. [PubMed: 10508238]

Liuzzi FJ, Miller RH. Radially oriented astrocytes in the normal adult rat spinal cord. Brain Res. 1987; 403(2):385-388. [PubMed: 2435373]

Lytton $\mathrm{J} . \mathrm{Na}^{+} / \mathrm{Ca}^{2+}$ exchangers: three mammalian gene families control $\mathrm{Ca}^{2+}$ transport. Biochem $\mathrm{J}$. 2007; 406(3):365-382. [PubMed: 17716241]

Malenka RC, Nicoll RA. Long-term potentiation--a decade of progress? Science. 1999; 285(5435): 1870-1874. [PubMed: 10489359]

Martone ME, Gupta A, Wong M, Qian X, Sosinsky G, Ludascher B, Ellisman MH. A cell-centered database for electron tomographic data. J Struct Biol. 2002; 138(1-2):145-155. [PubMed: 12160711]

Martone ME, Tran J, Wong WW, Sargis J, Fong L, Larson S, Lamont SP, Gupta A, Ellisman MH. The cell centered database project: an update on building community resources for managing and sharing 3D imaging data. J Struct Biol. 2008; 161(3):220-231. [PubMed: 18054501]

Mattson MP. Calcium and neurodegeneration. Aging Cell. 2007; 6(3):337-350. [PubMed: 17328689]

Neher E, Sakaba T. Multiple roles of calcium ions in the regulation of neurotransmitter release. Neuron. 2008; 59(6):861-872. [PubMed: 18817727]

Okunade GW, Miller ML, Pyne GJ, Sutliff RL, O’Connor KT, Neumann JC, Andringa A, Miller DA, Prasad V, Doetschman T, Paul RJ, Shull GE. Targeted ablation of plasma membrane $\mathrm{Ca}^{2+}$ ATPase (PMCA) 1 and 4 indicates a major housekeeping function for PMCA1 and a critical role in hyperactivated sperm motility and male fertility for PMCA4. J Biol Chem. 2004; 279(32): 33742-33750. [PubMed: 15178683]

Pappas CA, Ransom BR. Depolarization-induced alkalinization (DIA) in rat hippocampal astrocytes. J Neurophysiol. 1994; 72(6):2816-2826. [PubMed: 7897491]

Persechini A, Stemmer PM. Calmodulin is a limiting factor in the cell. Trends Cardiovasc Med. 2002; 12(1):32-37. [PubMed: 11796242]

Scheuss V, Yasuda R, Sobczyk A, Svoboda K. Nonlinear $\left[\mathrm{Ca}^{2+}\right]$ signaling in dendrites and spines caused by activity-dependent depression of $\mathrm{Ca}^{2+}$ extrusion. J Neurosci. 2006; 26(31):8183-8194. [PubMed: 16885232]

Schwaller B, Meyer M, Schiffmann S. 'New' functions for 'old' proteins: the role of the calciumbinding proteins calbindin D-28k, calretinin and parvalbumin, in cerebellar physiology. Studies with knockout mice. Cerebellum. 2002; 1(4):241-258. [PubMed: 12879963]

Sepúlveda MR, Berrocal-Carrillo M, Gasset M, Mata AM. The plasma membrane $\mathrm{Ca}^{2+}$-ATPase isoform 4 is localized in lipid rafts of cerebellum synaptic plasma membranes. J Biol Chem. 2006; 281(1):447-453. [PubMed: 16249176]

Simons SB, Escobedo Y, Yasuda R, Dudek SM. Regional differences in hippocampal calcium handling provide a cellular mechanism for limiting plasticity. Proc Natl Acad Sci U S A. 2009; 106(33):14080-14084. [PubMed: 19666491] 
Spitzer NC, Kingston PA, Manning TJ, Conklin MW. Outside and in: development of neuronal excitability. Curr Opin Neurobiol. 2002; 12(3):315-323. [PubMed: 12049939]

Stahl WL, Eakin TJ, Owens JW Jr, Breininger JF, Filuk PE, Anderson WR. Plasma membrane $\mathrm{Ca}^{2+}$ ATPase isoforms: distribution of mRNAs in rat brain by in situ hybridization. Brain Res Mol Brain Res. 1992; 16(3-4):223-231. [PubMed: 1337931]

Strehler EE. Plasma membrane $\mathrm{Ca}^{2+}$ pumps and $\mathrm{Na}^{+} / \mathrm{Ca}^{2+}$ exchangers. Semin Cell Biol. 1990; 1(4): 283-295. [PubMed: 2151738]

Strehler EE, Caride AJ, Filoteo AG, Xiong Y, Penniston JT, Enyedi A. Plasma membrane $\mathrm{Ca}^{2+}$ ATPases as dynamic regulators of cellular calcium handling. Ann N Y Acad Sci. 2007a; 1099:226-236. [PubMed: 17446463]

Strehler EE, Filoteo AG, Penniston JT, Caride AJ. Plasma-membrane $\mathrm{Ca}^{2+}$ pumps: structural diversity as the basis for functional versatility. Biochem Soc Trans. 2007b; 35(Pt 5):919-922. [PubMed: 17956246]

Strehler EE, Zacharias DA. Role of alternative splicing in generating isoform diversity among plasma membrane calcium pumps. Physiol Rev. 2001; 81(1):21-50. [PubMed: 11152753]

Verkhratsky A. The endoplasmic reticulum and neuronal calcium signalling. Cell Calcium. 2002; 32(5-6):393-404. [PubMed: 12543098]

West AE, Chen WG, Dalva MB, Dolmetsch RE, Kornhauser JM, Shaywitz AJ, Takasu MA, Tao X, Greenberg ME. Calcium regulation of neuronal gene expression. Proc Natl Acad Sci U S A. 2001; 98(20):11024-11031. [PubMed: 11572963]

Wouterlood FG, Mugnaini E. Cartwheel neurons of the dorsal cochlear nucleus: a Golgi-electron microscopic study in rat. J Comp Neurol. 1984; 227(1):136-157. [PubMed: 6088594]

Yang SN, Tang YG, Zucker RS. Selective induction of LTP and LTD by postsynaptic $\left[\mathrm{Ca}^{2+}\right] \mathrm{i}$ elevation. J Neurophysiol. 1999; 81(2):781-787. [PubMed: 10036277]

Yao H, Haddad GG. Calcium and $\mathrm{pH}$ homeostasis in neurons during hypoxia and ischemia. Cell Calcium. 2004; 36(3-4):247-255. [PubMed: 15261480] 


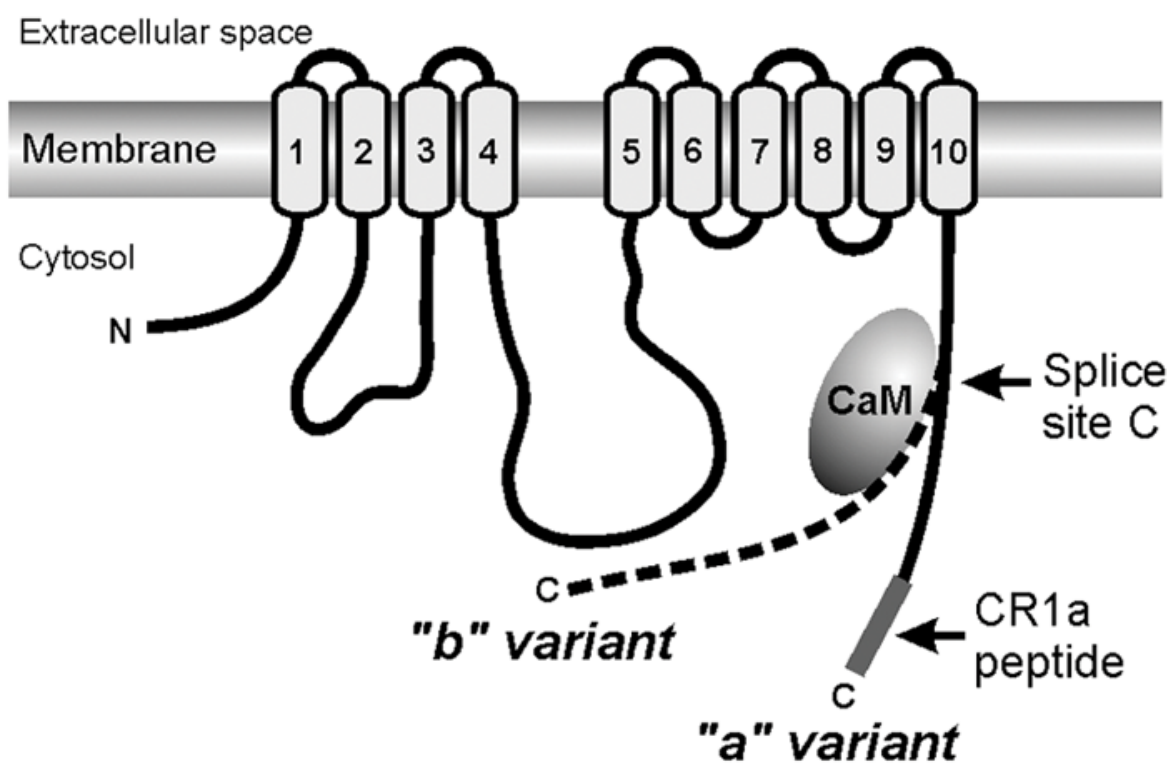

Figure 1. Diagram of PMCA1 in the plasma membrane illustrates its two alternative splice variants, "a" and "b"

The membrane-spanning segments are numbered 1-10. The position of the alternative splice site $\mathrm{C}$ is indicated by an arrow. The splice occurs in the middle of the calmodulin-binding domain; calmodulin $(\mathrm{CaM})$ is shown schematically as a hatched ellipse. The divergent $\mathrm{C}$ terminal tails of the "a" and " $b$ " variants are represented by separate lines, and the position of the CR1a antigenic peptide used to raise PMCA1a-specific antibodies is indicated by a thick black line. N, N-terminus; C, C-terminus. 
A
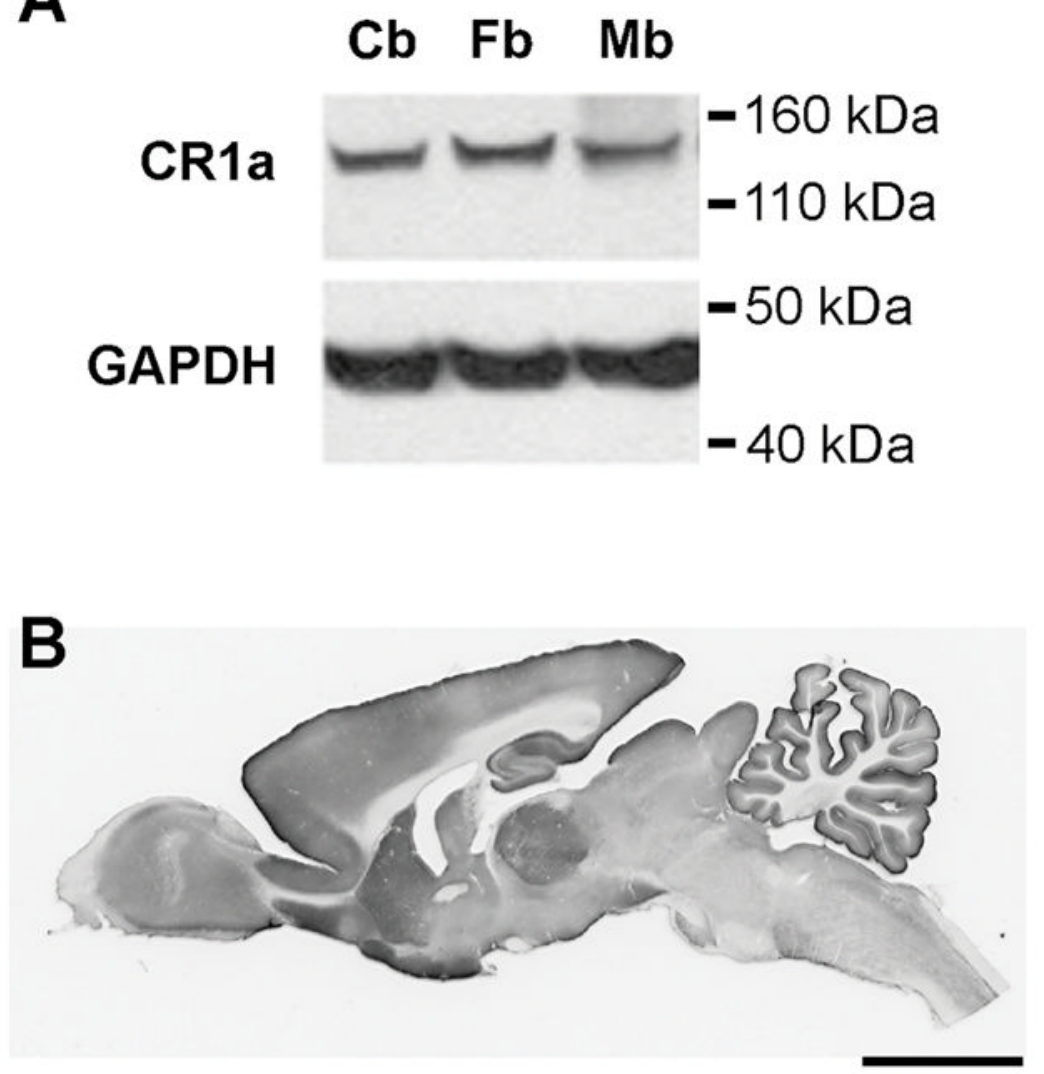

Figure 2. Distribution of PMCA1a in the adult rat brain

A: Western blots showing expression of PMCA1a in different regions of the rat brain. Thirty $\mu \mathrm{g}$ aliquots of protein lysate from cerebellum $(\mathrm{Cb})$, forebrain $(\mathrm{FB})$, and midbrain $(\mathrm{MB})$ were separated by SDS-polyacrylamide gel electrophoresis, blotted onto a PVDF membrane and probed with antibody CR1a for PMCA1a (top panel), and an antibody against GAPDH, to confirm equal loading of each lane (bottom panel). The position of molecular mass markers (in $\mathrm{kDa}$ ) is indicated on the left. PMCA1a was present and migrates at $\sim 130 \mathrm{kDa}$ in each brain region studied.

B: PMCA1a immunostaining in a parasagittal section.

PMCA1a staining was especially strong in neostriatum, thalamus and hippocampus. Staining was also prominent in the olfactory tubercle and the superficial layers of the superior colliculus.

Scale bar $=0.5 \mathrm{~cm}$ 


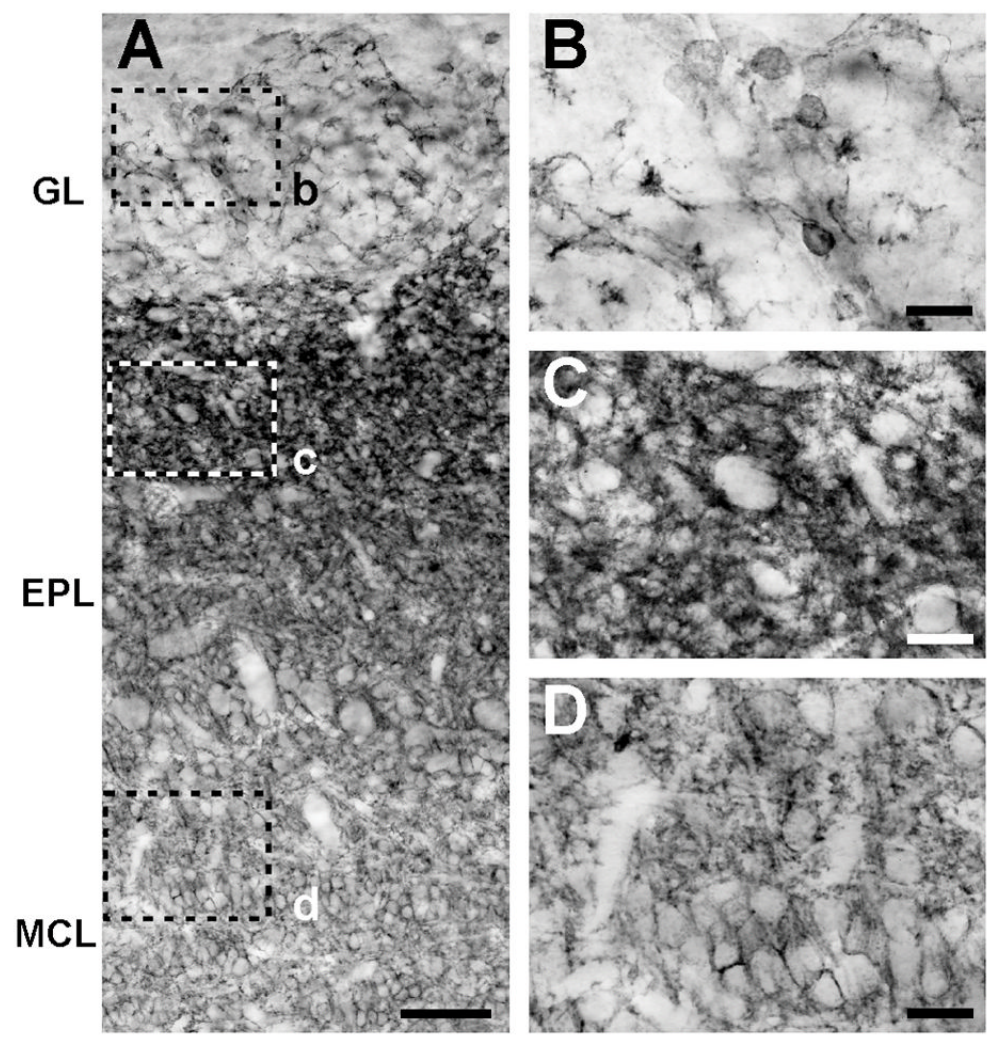

Figure 3. PMCA1a immunostaining in the olfactory bulb

All layers of the olfactory bulb stained for PMCA1a (A), but staining was most prominent in external plexiform layer (EPL). In the glomerular layer (GL), PMCA1a stained scattered cells and fine processes against a very weakly stained background (B). In EPL, staining filled a dense network of small processes (C). In the mitral cell layer (MCL), PMCA1a covered the cell somata; punctate staining was also present in the neuropil (D).

Scale bars: A, $200 \mu \mathrm{m} ; \mathbf{B}-\mathbf{D}, 50 \mu \mathrm{m}$. 

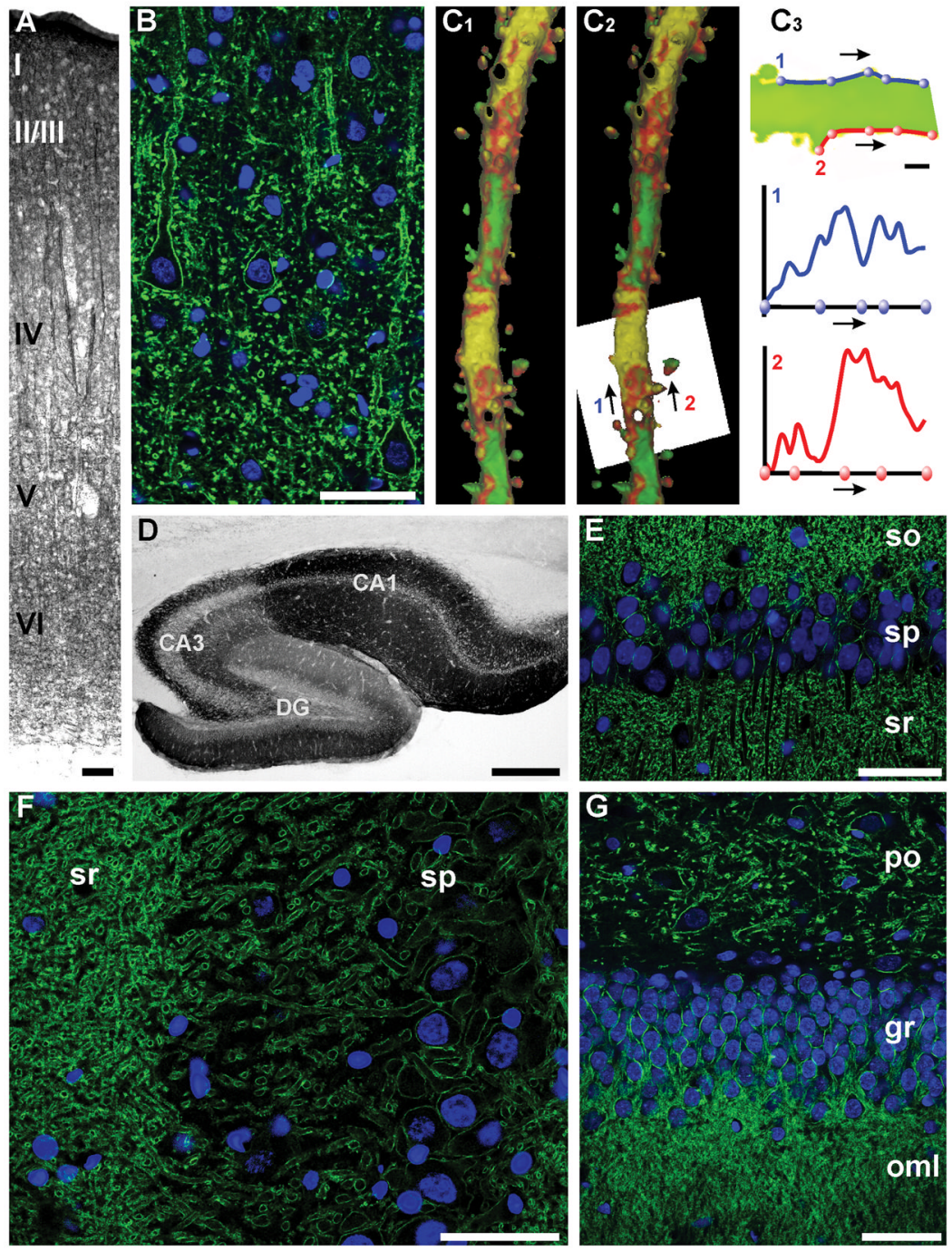

Figure 4. PMCA1a immunostaining in somatic sensory cortex and hippocampus

Staining for PMCA1a was present in all layers of the cerebral cortex, strongest in layers I-III and weaker in IV (A). Strongly immonopositive apical dendrites of layer V pyramidal neurons run through layer IV into superficial layers. Higher magnification view of layer $\mathrm{V}$ shows PMCA1a staining coating somatic and dendritic plasma membrane (B; green: PMCA1a; blue: DAPI). To better assess the distribution of PMCA1a in the plasma membrane, we applied the lipophilic membrane dye DiO to immunostained sections. Surface rendering of the $\mathrm{DiO}$ data set reveals the structure of an apical dendrite originating in layer V $(\mathbf{C 1})$. This 3D representation reveals regions of high (yellow to red) and low (red to green) concentration of PMCA1a in the dendrite. To assess whether PMCA1a intensity also varies within a small portion of the membrane, we extracted intensity values in a selected part of the membrane. The white plane in $\mathbf{C 2}$ represents a "slice extractor", which was interactively positioned through the dendrite. PMCA1a staining intensity was then sampled within the captured cross-section along two spline curves $(\mathbf{C 3})$. The splines follow the maximal intensity lines for $\mathrm{DiO}$ (yellow). Intensity plots demonstrate remarkable variations in PMCA1a staining intensity along the dendritic plasma membrane even within a small area. 
PMCA1a staining was present in all hippocampal regions. While PMCA1 was observed throughout Ammon's horn, it stained CA1 more strongly than CA2/3, as previously noted using the pan-PMCA1 antibody (Burette et al., 2003) (D). Staining was also strong in the outer blade of the dentate gyrus (DG, D). In CA1, PMCA1 a covered the somata and dendrites of pyramidal neurons $(\mathbf{E})$. Staining was qualitatively similar in CA3 (F), but the staining was weaker. In the dentate gyrus, PMCAla staining was strongest in the granule cell layer and the outer molecular layer, where it covered the somata and dendrites of granule cells $(\mathbf{G})$. Though less dense in the polymorphic layer, somato-dendritic staining was obvious.

DG, dentate gyrus; so, stratum oriens; sp, stratum pyramidale; sr, stratum radiatum; gr, granular cell layer; oml, outer molecular layer; po, polymorphic cell layer.

Scale bars: A, D-G, $50 \mu \mathrm{m} ; \mathbf{B}, 500 \mu \mathrm{m} ; \mathbf{C 3}, 2 \mu \mathrm{m}$. 

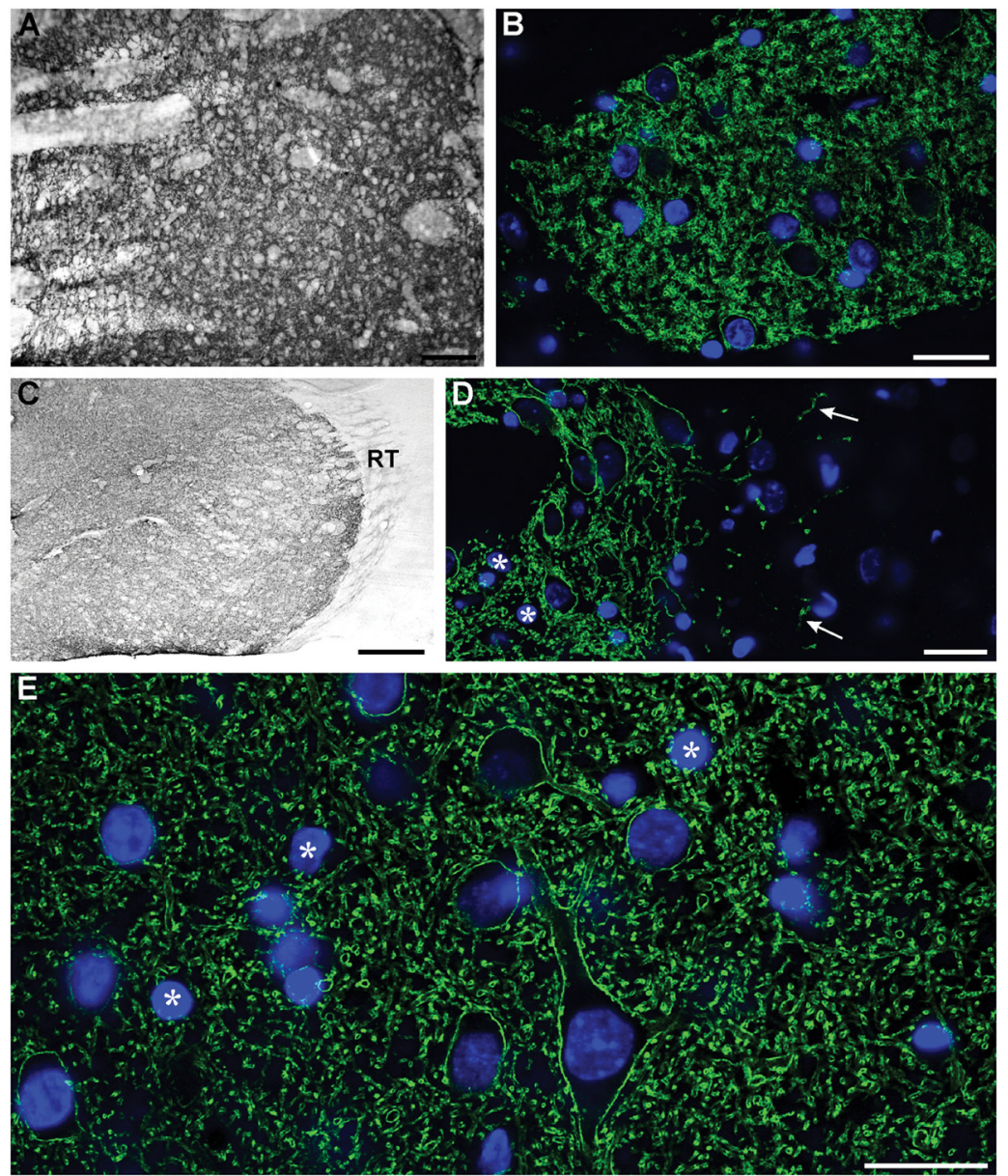

Figure 5. PMCA1a immunostaining in the neostriatum and thalamus

In the neotriatum, PMCA1a staining was confined to neuropil between the fascicles, which themselves were devoid of staining (A). At high magnification, PMCA1a staining could be seen on the surface of somata and dendrites $(\mathbf{B})$.

In the thalamus, PMCA1a staining was strong in the ventrobasal nuclear complex and weak in the reticular nucleus $(\mathbf{C})$. In the ventrobasal nucleus, PMCA1a covered the surface of somata and dendrites, though some somata were PMCA1a-negative (asterisks in D). The reticular nucleus contained only a few PMCA1a-positive processes (arrows in D). In the posterior complex, numerous somata and dendrites were surrounded by intense PMCA1a staining, but a number of somata appeared PMCA1a-negative (asterisks in E).

$\mathrm{RT}$, reticular thalamic nucleus.

Scale bars: A, $100 \mu \mathrm{m} ; \mathbf{B}, 25 \mu \mathrm{m} ; \mathbf{C}, 250 \mu \mathrm{m} ; \mathbf{D}, \mathbf{E}, 25 \mu \mathrm{m}$. 

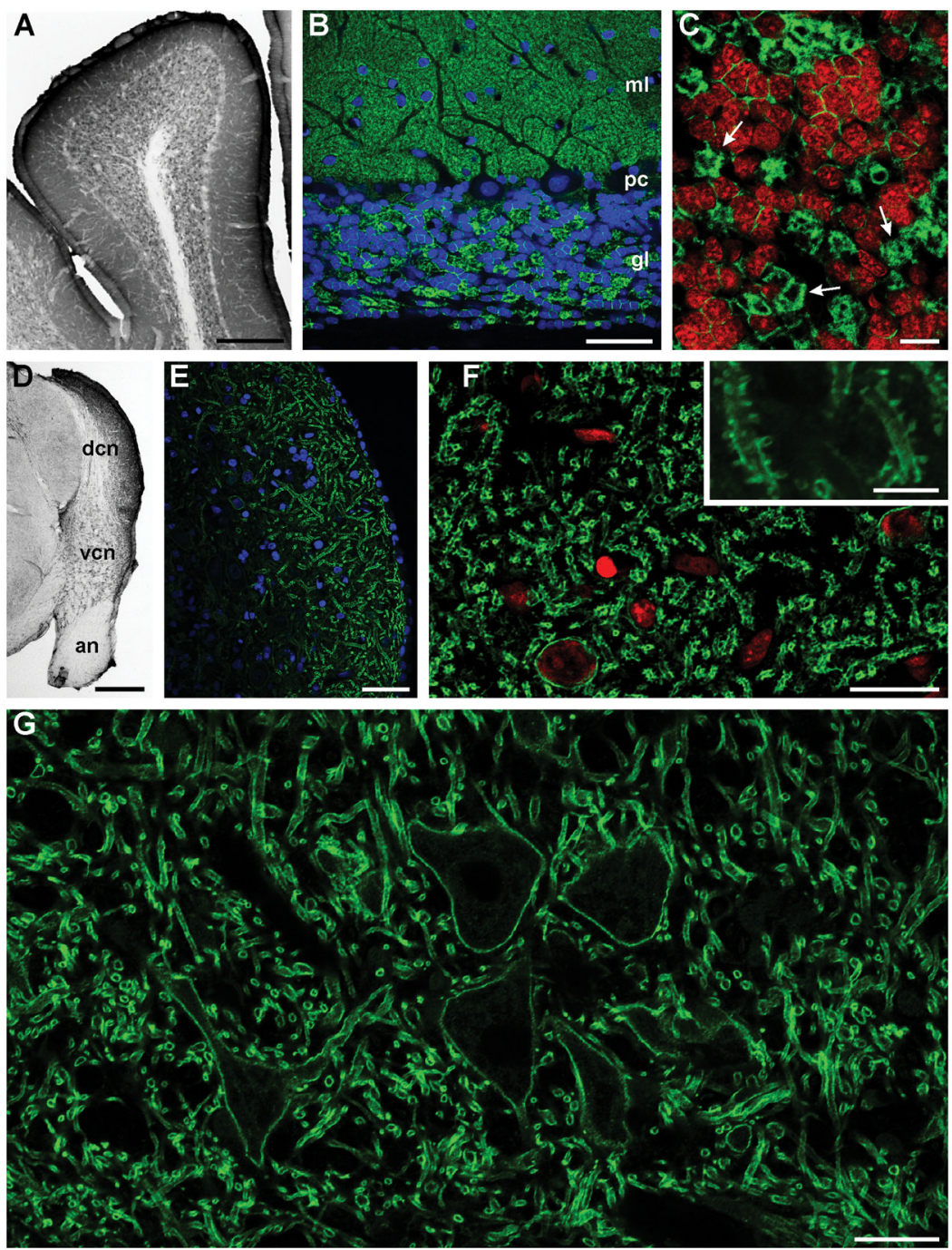

Figure 6. PMCA1a immunoreactivity in the cerebellum and brain stem

In cerebellum, PMCA1a staining was strongest in the molecular and granule cells layers; the white matter lacked staining (A). At intermediate magnification (B), PMCA1a staining defined Purkinje cell somata and their proximal dendrites; punctate staining was seen throughout the molecular layer. Granule cells were covered with PMCA1a staining. Staining was also strong in synaptic glomeruli (arrows in $\mathbf{C}$ ).

In the brain stem, PMCA1a staining was remarkably strong in the dorsal cochlear nucleus (D), especially at the surface of the nucleus (E). Higher magnification reveals association of PMCA1a with somata of small round cells and dendrites (F, PMCA1a, green, NeuroTrace, red). PMCA1a labeling was seen both in dendritic trunks and in spines (inset in $\mathbf{F}$ ).

PMCA1a staining was also strong in the facial nucleus, where the somata of motor neurons were outlined by intense staining $(\mathbf{G})$. Staining was also associated with numerous hollow round profiles, presumably cross-sections of large dendrites.

$\mathrm{ml}$, molecular layer; pc, Purkinje cells layer; gl, granular layer; dcn, dorsal cochlear nucleus; vcn, ventral cochlear nucleus; an, auditory nerve.

Scale bars: A, $500 \mu \mathrm{m} ; \mathbf{B}, 25 \mu \mathrm{m} ; \mathbf{C}, 10 \mu \mathrm{m} ; \mathbf{D}, 500 \mu \mathrm{m} \mathbf{E}, 50 \mu \mathrm{m} ; \mathbf{F}, 25 \mu \mathrm{m}$; F inset, $5 \mu \mathrm{m}$; G, $25 \mu \mathrm{m}$. 
A magenta-green version of this figure has been posted online as a Supporting Figure for the assistance of color-blind readers. 

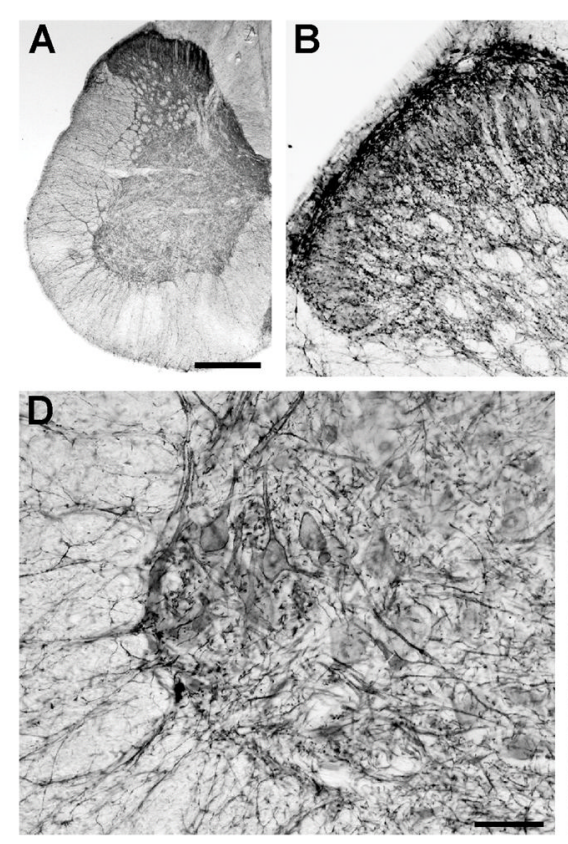

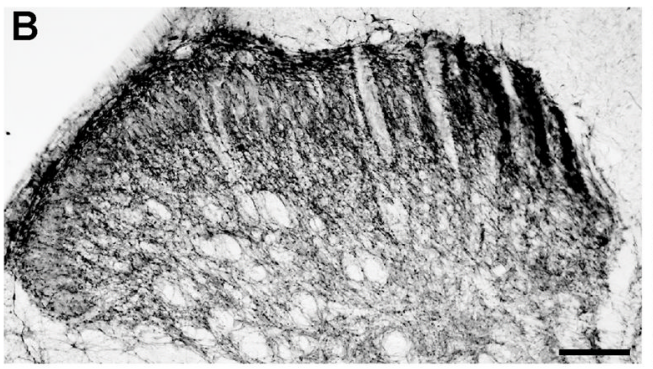

E

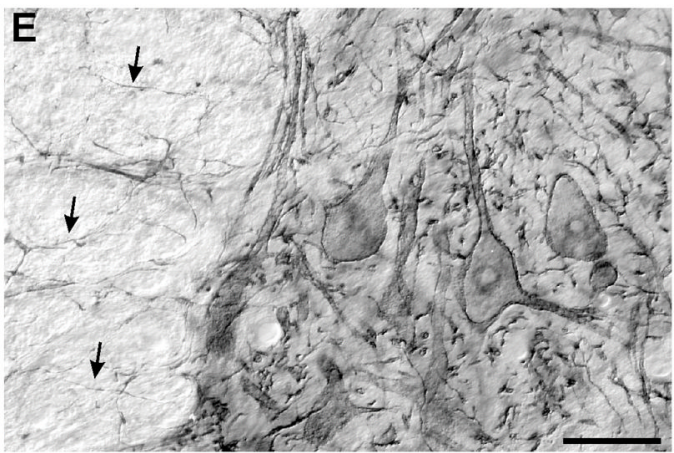

Figure 7. PMCA1a immunoreactivity in the spinal cord

In the spinal cord, PMCA1a staining was strong in the dorsal horn (A), strongest in layer I, and weaker in lamina II (B). At higher magnification, PMCA1a staining was associated with numerous thin processes, and the somata of some small cells $(\mathbf{C})$. In the ventral horn, motor neurons were outlined by PMCAa staining $(\mathbf{D}, \mathbf{E})$. $\mathbf{D}$ and $\mathbf{E}$ are shown with differential interference contrast illumination, to facilitate identification of unstained structures. Arrows in $\mathbf{E}$ indicate thin PMCA1a-positive processes radiating toward the ependyma.

Scale bars: A, $500 \mu \mathrm{m} ; \mathbf{B}, 100 \mu \mathrm{m} ; \mathbf{C}, 20 \mu \mathrm{m} ; \mathbf{D}, 50 \mu \mathrm{m} ; \mathbf{E}, 20 \mu \mathrm{m}$. 

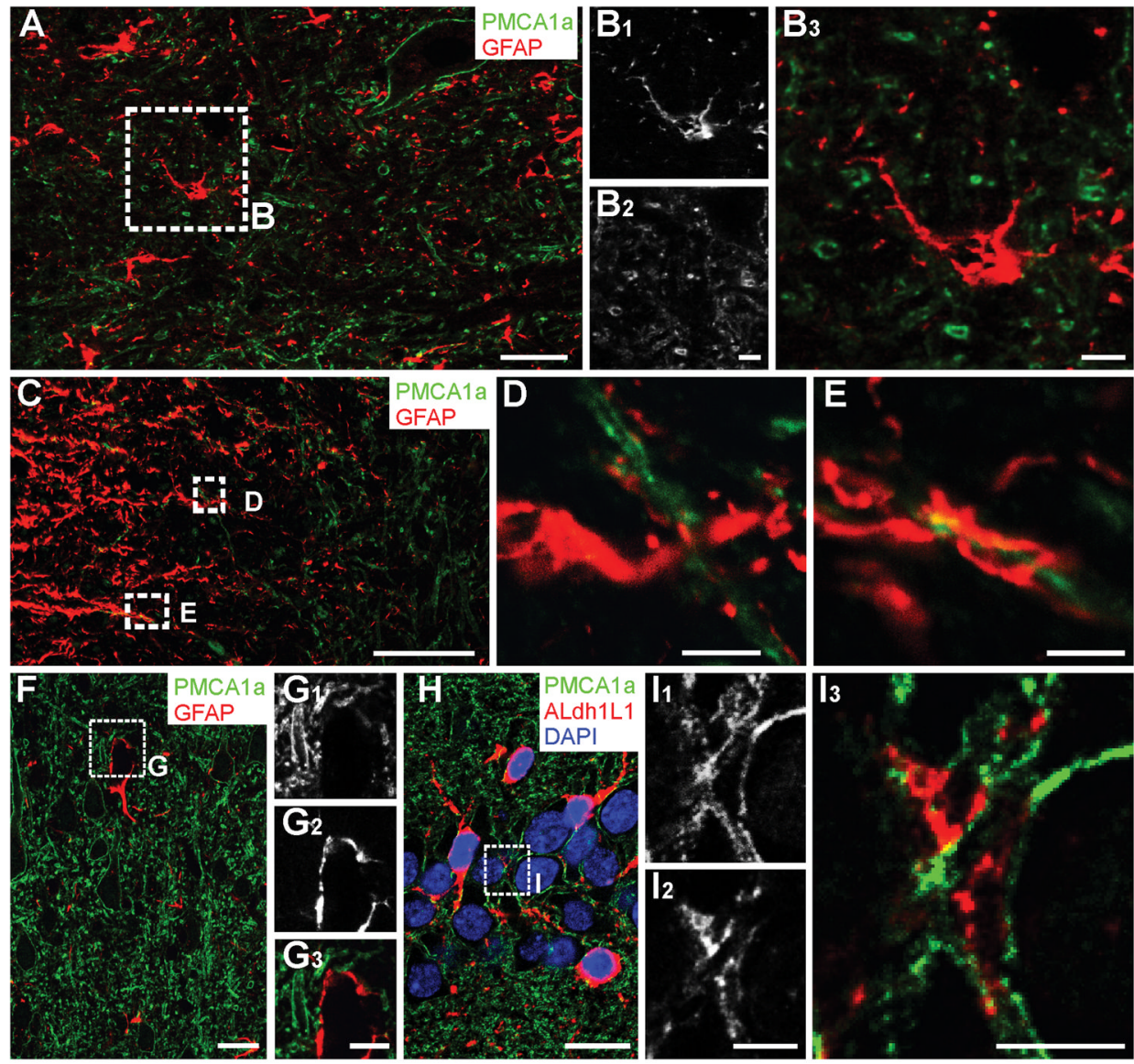

Figure 8. Double labeling for PMCA1a and astrocytic markers in the spinal cord (A-E), cerebral cortex $(F, G)$, and the hippocampus $(H, I)$

In the gray matter of the spinal cord, protoplasmic astrocytes stained for GFAP (red), but were immunonegative for PMCA1a (green, A, B). In the white matter, fibrous astrocytic processes closely followed the PMCA1a positive processes but were themselves negative for PMCA1a (C-E). Likewise, in the cerebral cortex $(\mathbf{F}, \mathbf{G})$ and hippocampus $(\mathbf{H}, \mathbf{I})$ colocalization of PMCA1a (green) with either GFAP (red) or AlDh1L1 (red) was not observed.

Scale bars: A, $25 \mu \mathrm{m} ; \mathbf{B}, 5 \mu \mathrm{m} \mathbf{C}, 50 \mu \mathrm{m} ; \mathbf{D}, 5 \mu \mathrm{m} ; \mathbf{F}, \mathbf{E}, 25 \mu \mathrm{m} ; \mathbf{G}, 10 \mu \mathrm{m} ; \mathbf{H}, 20 \mu \mathrm{m} ; \mathbf{I}, 5$ $\mu \mathrm{m}$.

A magenta-green version of this figure has been posted online as a Supporting Figure for the assistance of color-blind readers. 


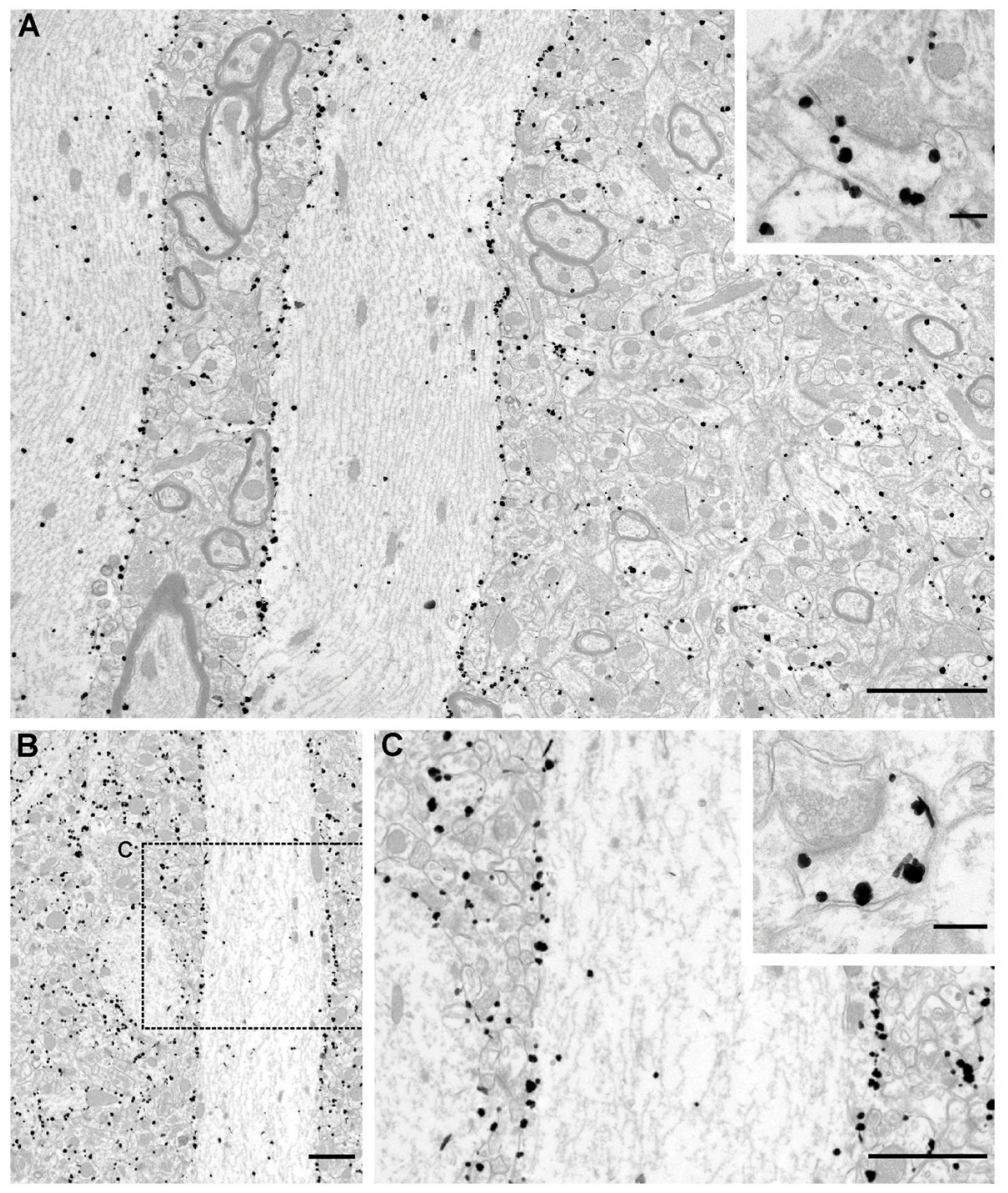

Figure 9. Subcellular distribution of PMCA1a

In both cerebral cortex $(\mathbf{A})$ and the hippocampus $(\mathbf{B}, \mathbf{C})$ silver-enhanced gold particles are largely restricted to the membrane. Scattered gold/silver particles in the cytoplasm are associated with microtubules. Numerous gold/silver particles coated the membrane of somata and dendrites. Staining in dendrites, extended into spine membrane (inset in $\mathbf{A}$ and C).

Scale bars: A-C, $2 \mu \mathrm{m}$; insets, $250 \mathrm{~nm}$. 